\title{
La transferencia de células madres al recién nacido mediante la trasfusión placentaria a través del clampeo demorado del cordón umbilical
}

\author{
Stem cell transfer in newborn infants through placental transfusion via delayed \\ umbilical cord clamping
}

Hasta hace pocos años, la medicina no pudo determinar cuál era el momento apropiado para efectuar el clampeo del cordón umbilical. Desde hace más de dos siglos persistieron las controversias entre elegir el clampeo inmediato o temprano, primeros 15 segundos, o el demorado, dos a tres minutos o más.

Recién en los primeros años de este siglo, surgieron estudios aleatorizados controlados y revisiones sistemáticas, que aportaron sólidas evidencias de los indiscutibles beneficios del clampeo demorado y la ausencia de efectos perjudiciales. ${ }^{1,3}$

Aun así pasaron varios años para que las Sociedades Científicas se decidieran a avalar las recomendaciones de que debía emplearse el clampeo demorado, probablemente porque durante varias décadas se instalaron normas y guías que firmemente recomendaban el clampeo temprano. Esto ocurrió aun cuando no había ningún sustento que avalara el uso de esa práctica y se difundió a la gran mayoría de los países occidentales luego de varias publicaciones de estudios con escasos pacientes e inadecuadamente diseñados, que señalaron enfáticamente que el clampeo demorado era perjudicial.

Lo increíble de estas posiciones tan distantes es que no eran cuestionadas, como suele ser cuando se discute acerca de alguna enfermedad o tratamiento, que suelen generar controversias. Por el contrario, lo que estaba en juego era algo absolutamente natural en los mamíferos, entre ellos, nosotros, pero lamentablemente eso no fue advertido y privó el desconocimiento de los mecanismos fisiológicos que participan en la adaptación del recién nacido a la vida extra uterina.

Deseo decir que es lamentable que en la era de la medicina moderna, plena de avances importantes, se haya sostenido al menos en los últimos 50 años que debía aplicarse el clampeo inmediato del cordón umbilical. Sin duda que la recomendación masiva de esa práctica en la medicina occidental fue un lamentable y grave error que produjo enormes perjuicios a muchos recién nacidos y niños.

Afortunadamente, en los últimos años, ha crecido en marcadamente el interés en estudiar los procesos fisiológicos presentes en los primeros minutos posteriores al nacimiento y de los cuales depende la adecuada transición a la vida extrauterina. Varios estudios observaron que el clampeo demorado del cordón (entre 2 a 3 minutos) tiene una acción muy beneficiosa al promover la función de los mecanismos fisiológicos que participan en la adaptación al nacer. Se sabe que cuando el recién nacido no ha respirado espontáneamente es vital mantener sin pinzar el cordón hasta después de la primera respiración ya que la transfusión de sangre que recibe desde la placenta mejorará la función cardiovascular al aumentar el flujo sanguíneo pulmonar. Esto permitirá que el gasto cardíaco no disminuya, que es el factor esencial para una adecuada transición cardiovascular y respiratoria en los primeros minutos de vida. ${ }^{4,5}$ Las acciones señaladas se relacionan con lo hallado en una investigación que demostró que en los prematuros pequeños el clampeo demorado mejoraba la oxigenación cerebral en las primeras 24 horas de vida. ${ }^{6}$

Por el contrario, el clampeo inmediato o temprano impide que estén presentes todos los mecanismos fisiológicos que la naturaleza ha puesto en los mamíferos desde que estamos en la tierra.

Luego de esta introducción, abordaré ahora otro aspecto de una inmensa trascendencia en el desarrollo del recién nacido, el niño e incluso el adulto. La transfusión placentaria no solo participa en lo que brevemente hemos señalado sino que además permite que el neonato reciba una notable cantidad de células madres (stem cells) que llegan en la sangre del cordón umbilical.

Este maravilloso y fascinante proceso fisiológico solo puede concretarse plenamente si el clampeo del cordón se realiza luego de unos minutos y de esa forma permite un pasaje sumamente mayor de células madres, que nuevamente la naturaleza ha decidido que les corresponden al recién nacido. Se calcula que el número de células madres hematopoyéticas que recibe el neonato son de 0 con el clampeo 
inmediato y entre 1100 a 45000 con el clampeo a los tres minutos. ${ }^{7}$

Es de destacar un aspecto de gran magnitud, los prematuros muy pequeños (menos de 31 semanas al nacer) reciben a través de la transfusión placentaria una notable cantidad de células eritropoyéticas progenitoras. Haneline et al. observaron que la proliferación de células madres en la sangre de prematuros pequeños era significativamente mayor que en los nacidos al término y sorprendentemente también era mayor que en la médula ósea de adultos. Es decir que esos prematuros tenían la más alta proliferación de stem cells en el ser humano Los autores señalan también algo de suma relevancia, las células de la sangre de cordón fetal pueden resultar objetivos útiles para la manipulación genética y el trasplante autólogo. ${ }^{8}$

Un interesante artículo referido a este tema, llevó el muy sugestivo título "El primer trasplante natural de células madre de la humanidad". ${ }^{9}$ Los autores destacan la importante proliferación de células madres pluripotenciales en el feto después del nacimiento y posteriormente, y que eso solo se puede obtener con el importante volumen de sangre que llega al neonato (entre 25 a $35 \mathrm{ml} / \mathrm{kg}$ ) a través del clampeo demorado. También destacan que la sangre del cordón umbilical tiene suficientes células madres hematopoyéticas para ser empleadas en trasplantes, aunque es necesario contar con más experiencia. También destacan que la sangre del cordón tendría un importante y trascendente rol como reservorio de células pluripotenciales para proporcionar una variedad de células madres, tales como hematopoyeicas, endoteliales precursoras, progenitoras mesenquimales y pluripotenciales, y las células madres de linaje multipotente.

Quiero señalar que el primer trasplante de sangre del cordón umbilical humana se realizó en un varón de 16 años de edad con leucemia linfoblástica aguda en $1972 .{ }^{10}$ Luego, las células madre del cordón se han trasplantado con éxito para tratar una variedad de trastornos pediátricos, genéticos, hematológicos, inmunológicos, metabólicos y oncológicos

Asimismo, en forma independiente, las células madre desempeñan desde mucho tiempo antes de nacer, un papel esencial en el desarrollo y la madurez de muchos órganos, incluyendo el sistema nervioso central, respiratorio, hematológico, inmunológico y endócrino. También actúan sobre la maduración en el feto y el recién nacido, en la acción anti inflamatoria e infecciosa, y en reducir varias enfermedades.

Los beneficios confirmados de estas células en neonatos son: síndrome de dificultad espiratoria, anemia de la prematuridad, hemorragia intraventricular, sepsis y leucomalacia periventricular. Es muy probable que tengan efectos beneficiosos en la enfermedad pulmonar crónica, apneas de la prematuridad, retinopatía del prematuro y enterocolitis necrozante.

Estas acciones, en especial en prematuros muy pequeños, enfatizan que el clampeo demorado del cordón tiene una gran trascendencia al disminuir la morbilidad y mortalidad en los primeros meses. Por lo tanto no hay justificaciones que impidan esa práctica, que es segura, sin costo y solo necesita unos pocos minutos.

Es de reiterar que la mayoría de los beneficios de las stem cells del cordón umbilical no actúan solamente en el período neonatal sino posteriormente en niños y adultos.

Sin duda, se trata de una fascinante línea de investigación que en los próximos años brindará nuevos resultados en recién nacidos y niños. Mientras tanto, los obstetras, neonatólogos y pediatras debemos practicar y promover el clampeo demorado del cordón umbilical ya que, como vimos, provee enormes beneficios.

\section{José M. Ceriani Cernadas} Editor

http:/ / dx.doi.org/10.5546/aap.2016.498

Texto completo en inglés: http:/ / dx.doi.org/10.5546/ aap.2016.eng.498

\section{REFERENCIAS}

1. Chaparro CM, Neufeld LM, Tena Alvarez G, Eguia-Liz CR, ET al. Effect of timing of umbilical cord clamping on iron status in Mexican infants: a randomised controlled trial. Lancet 2006;367(9527):1997-2004.

2. Ceriani Cernadas JM, Carroli G, Pellegrini L, Otaño L, et al. The effect of timing of cord clamping on neonatal venous hematocrit values and clinical outcome at term: a randomized, controlled trial. Pediatrics 2006;117(4):e779-86.

3. McDonald SJ, Middleton P, Dowswell T, Morris PS. Effect of timing of umbilical cord clamping of term infants on maternal and neonatal outcomes. Cochrane Database Syst Rev 2013;(7):CD004074.

4. Kluckow M, Hooper SB. Using physiology to guide time to cord clamping. Semin Fetal Neonatal Med 2015;20(4):225-31.

5. Hooper SB, Binder-Heschl C, Polglase GR, Gill AW, et al. The timing of umbilical cord clamping at birth: physiological considerations. Matern Health Neonatol Perinatol 2016;13;2:4 .

6. Baenziger O, Stolkin F, Keel M, von Siebenthal K, et al. The influence of the timing of cord clamping on postnatal cerebral oxygenation in preterm neonates: a randomized, controlled trial. Pediatrics 2007;119(3):455-9.

7. Lawton C, Acosta S, Watson N, González Portillo C, et al. Enhancing endogenous stem cells in the newborn via delayed umbilical cord clamping. Neural Regen Res 2015;10(9):1359-62.

8. Haneline LS, Marshall KP, Clapp DW. The highest concentration of primitive hematopoietic progenitor cells in cord blood is found in extremely premature infants. Pediatr Res 1996;39(5):820-5.

9. Tolosa JN, Park DH, Eve DJ, Klasko SK, et al. Mankind's first natural stem cell transplant. J Cell Mol Med 2010;14(3):488-95.

10. Chakraborty SK, Banu LA, Rahman MF, PaulS. Cord blood stem cells - a dream for future medicine. Mymensingh Med J 2014;23(3):614-20. 